\title{
PRODUÇÃO E EXTRAÇÃO DE $\beta$-CAROTENO EM CULTIVO HETEROTROFICO DE MICROALGA PHORMIDIUM SP.
}

\author{
A. S. FERNANDES ${ }^{1}$, S. R. KACHUK-SILVA ${ }^{1}$, D. B. RODRIGUES ${ }^{1}$, A. B. SANTOS ${ }^{1}$, \\ E. JACOB-LOPES ${ }^{1}$, L. Q. ZEPKA ${ }^{1}$. \\ ${ }^{1}$ Universidade Federal de Santa Maria, Departamento Tecnologia e Ciência dos Alimentos \\ E-mail para contato: lqz@pq.cnpq.br E-mail: zepkaleila@yahoo.com.br
}

\begin{abstract}
RESUMO - O cultivo de microalga em meios heterotróficos é uma alternativa promissora para obtenção de pigmentos como o $\beta$-caroteno. Assim, o objetivo do trabalho foi a quantificação deste pigmento em larga escala a partir da biomassa de microalga Phormidium sp. A produção desse pigmento foi conduzida através do cultivo heterotrófico, utilizando água residuária como meio. A extração do $\beta$-caroteno foi obtido por ultra-som (Sonics, Anaheim, CA, EUA) com sonda de $13 \mathrm{~mm}$ de diâmetro. Os isômeros foram quantificados de acordo com os seguintes parâmetros: ordem de eluição na coluna C30 de HPLC, cromatografia com padrões autênticos, e espectros de massa. All-trans- $\beta$-caroteno $\left(70,22 \pm 0,4 \mu \mathrm{g} . \mathrm{g}^{-1}\right)$ e 9 -cis- $\beta$-caroteno $\left(8,0 \pm 0,1 \mu \mathrm{g} \cdot \mathrm{g}^{-1}\right)$ a partir da biomassa. Visando uma escala industrial a partir do cultivo heterotrófico de $10,000 \mathrm{~m}^{3} / \mathrm{d}$, estima-se uma produção all-trans- $\beta$-caroteno $7.902,5 \mathrm{~kg} /$ ano e 4.944,7 kg/ano de 9-cis- $\beta$ caroteno apresentando assim valores de alta rentabilidade no beneficiamento deste tipo de pigmento comparados com a produção em meio autotrófico.
\end{abstract}

\section{INTRODUÇÃO}

O crescente interesse em pigmentos naturais produzidos de forma alternativa que não concorra com os suprimentos de culturas agrícolas convencionais, incentiva o desenvolvimento de tecnologias que empregam microrganismos cultivados de forma heterotrófica. As microalgas apresentam uma ampla versatilidade metabólica o que contribui para a habilidade de sintetizar em quantidades consideráveis carotenoides (Albrecht et al., 2009; Mandelli et al., 2012).

As principais fontes industriais de carotenoides são a síntese química e a extração a partir de plantas e microalgas. As formas sintéticas de obtenção são menos onerosas que as naturais, no entanto, carotenoides provenientes da biomassa microalgal apresentam vantagens, como a de possuir uma razão natural de all-trans/isômeros (Spolaore, 2006).

O $\beta$-caroteno é um pigmento amplamente distribuído na natureza, encontrado principalmente em tecidos de plantas, animais e microrganismos. Possui uma ampla aplicação industrial em função da cor e por possuir propriedades bioativas (Britton, 1983; Britton, 2004). 


\section{9 a 22 de outubro de 2014 \\ Florianópolis/SC}

A produção comercial de carotenoides usando microrganismos é uma alternativa promissora e altamente eficiente. Diferentes microrganismos fotossintetizantes, como algas e cianobactérias demostram potencial de produção de $\beta$-caroteno (Silva, 2004; Johnson e Schroeder, 1995). Sob mudanças nas condições ambientais (por exemplo, privação de nutrientes, a limitação de luz), microalgas podem sofrer condições de stress, levando-as a produzir alguns compostos de interesse, onde destacam se os carotenoides (López et al., 2013).

Para a produção de biomassa microalgal, fotobiorreatores são amplamente utilizados, entretanto, em culturas de grande escala, a absorção de luz é atenuada pelo sombreamento mútuo das células, afetando seriamente a produtividade e a qualidade dos produtos da biomassa das algas (Markou e Georgakakis, 2011), além do custo elevado da energia elétrica (Ip e Chen, 2005). Então uma alternativa para este processo seria o cultivo heterotrófico, a partir do qual o fornecimento energético para os microrganismos seria uma assimilação de uma fonte de carbono, como por exemplo, açúcares. Desta forma, a associação entre o tratamento de águas residuárias e a produção de bioprodutos a partir da biomassa microalgal pode representar um significativo avanço na direção de reduzir os custos de produção.

Da mesma forma que há a necessidade de pesquisas visando o desenvolvimento e o aperfeiçoamento dos sistemas de produção, a fim de torna-los viáveis economicamente, também se faz necessária à identificação e quantificação dos produtos que possam ser extraídos das microalgas, bem como suas possíveis atividades biológicas, para que este sistema se estabeleça. Embora a cianobactéria Phormidium sp. tenha a habilidade de se desenvolver em cultivos heterotróficos, não há informações disponíveis sobre os compostos desta biomassa produzida no escura, principalmente quanto ao perfil de carotenoides. Em fase disso o presente trabalho tem como objetivo a quantificação e o potencial de produção do $\beta$-caroteno em larga escala a partir da biomassa da microalga Phormidium sp.

\section{METODOLOGIA}

\subsection{Microrganismos e meios de cultura}

Culturas da cianobactéria Phormidium sp. foram originalmente isoladas do deserto Cuatro Cienegas no México $\left(26^{\circ} 59^{\prime} \mathrm{N} 102^{\circ} 03 \mathrm{~W}\right)$. As culturas de reserva foram propagadas e mantidas em solidificado de agar-agar (20 g/L) contendo meio BGN11 sintético (Rippka et al., 1979). As condições de incubação usadas foram de $25^{\circ} \mathrm{C}$, uma densidade de fluxo de fótons de 15 $\mu$ molm $^{-2} \mathrm{~s}^{-1}$ e foto período de 12 horas de luz/escuro.

\subsection{Produção de biomassa de microalgas}

A produção de biomassa foi realizada em condições heterotróficas, utilizando a água residuária de abate de suínos como meio de cultura. As culturas foram realizadas em reator de biorreator bolhas (Francisco et al, 2014), operando em regime de batelada utilizando 2,0 L de água residual como meio de cultura. As condições experimentais foram as seguintes: 


\section{9 a 22 de outubro de 2014 \\ Florianópolis/SC}

concentração inicial do inóculo de $100 \mathrm{mg} / \mathrm{L}$, a temperatura de $26^{\circ} \mathrm{C}$, o pH 7,6, a razão de carbono/nitrogênio de 30 (ajustado com glicose), na ausência de luz e um tempo de residência de 168 horas. A biomassa foi separada do efluente por centrifugação. Posteriormente, foi liofilizado. Os cultivos foram realizados em duplicata.

\subsection{Métodos analíticos}

\subsubsection{Extração de carotenoides}

Os carotenóides foram extraídos por extração assistida por ultrassom (UAE) utilizando um processador ultra-sônico (Sonics, Anaheim, CA, EUA) com uma sonda de $13 \mathrm{~mm}$ de diâmetro. As amostras secas $(0,2 \pm 0,2 / \mathrm{g})$ foram colocadas em um recipiente revestido, através do qual a água foi circulada a $20{ }^{\circ} \mathrm{C}$. As extrações foram realizadas com acetona fria durante 20 minutos e a amplitude da aplicação de extração foi ajustado para 50\% (61 $\mu \mathrm{m}$ aproximadamente). As amostras foram processadas em uma frequência constante de $20 \mathrm{kHz}$. A sonda do ultra-som foi submersa a uma profundidade de $25 \mathrm{~mm}$ na amostra. A suspensão da amostra foi centrifugada durante 10 min a $3000 \mathrm{rpm}$. O procedimento de extração foi repetido até o sobrenadante se tornar incolor. Os carotenóides foram transferidos para uma mistura de éter de petróleo/éter dietílico [1:1 (v / v)], e saponificado por 12h com 10\% (w/v) de hidróxido de potássio (KOH) em metanol, à temperatura ambiente. $\mathrm{O}$ meio alcalino foi removido por lavagem do extrato com água destilada e o extrato concentrado em evaporador rotativo $\left(\mathrm{T}<30{ }^{\circ} \mathrm{C}\right)$ e posteriormente armazenado em atmosfera saturada de nitrogênio até o momento da análise cromatográfica.

\subsubsection{Análise HPLC-DAD-MS/MS}

Os carotenóides foram analisados por cromatografia líquida de alta eficiência HPLC (Shimadzu, Kyoto, Japão) equipado com bombas quaternárias (modelo LC- 20AD), desgaseificador em linha, e válvula de injeção com um loop de $20 \mu \mathrm{L}$ (Rheodyne, Rohnert ParkCA, EUA). O equipamento foi ligado em série a um detector de PDA (modelo SPD - M20A) e um espectrômetro de massas com um analisador de "íon trap" em ionização química a pressão atmosférica (APCI) (modelo Esquire 4000, Bruker Daltonics, Bremem, Alemanha). Os espectros de UV-visível foram obtidos entre 250 e $600 \mathrm{~nm}$, e os cromatogramas foram processados a 451 $\mathrm{nm}$. Os parâmetros de MS foram definidos de acordo previamente descritos por Zepka e Mercadante, 2009. A separação dos carotenóides foi realizada em uma coluna C30 YMC (5 $\mu \mathrm{m}$, 250 x $4.6 \mathrm{~mm}$ id) (Waters, Wilmington, DE, EUA ).

A identificação foi realizada de acordo com a seguinte combinação das informações: ordem de eluição na coluna C30 de HPLC, co-cromatografia com padrões, as características de espectro de UV - visível [comprimento de onda de absorção máxima ( $\lambda$ máx), estrutura fina espectral (\% III / II) e cis pico intensidade (\% AB/AI)] e as características dos espectros de massa (moléculas protonadas e os seus fragmentos MS/MS). Estes resultados foram comparados com 
padrões e dados autênticos disponíveis na literatura (Britton et al, 2004; De Rosso e Mercadante, 2007; Zepka e Mercadante , 2009; Van Breemen et al, 2012).

Os carotenóides foram quantificados usando curvas analíticas de cinco pontos com alltrans- $\beta$-caroteno (1.1-30.2 $\mu \mathrm{g} / \mathrm{mL})$. Os isômeros cis foram estimados usando a curva da correspondente all-trans- carotenóides. O teor total de carotenóides foi calculado como a soma dos conteúdos de cada um dos carotenóides individuais separados na coluna C30.

\section{RESULTADOS E DISCUSSÃO}

O cromatograma obtido pela análise em HPLC (Figura 1) demonstra a presença de vinte carotenóides no extrato da biomassa de Phormidium sp., os quais foram identificados All-trans- $\beta$ caroteno e 9-cis- $\beta$-caroteno com base nas informações obtidas na coluna C30.

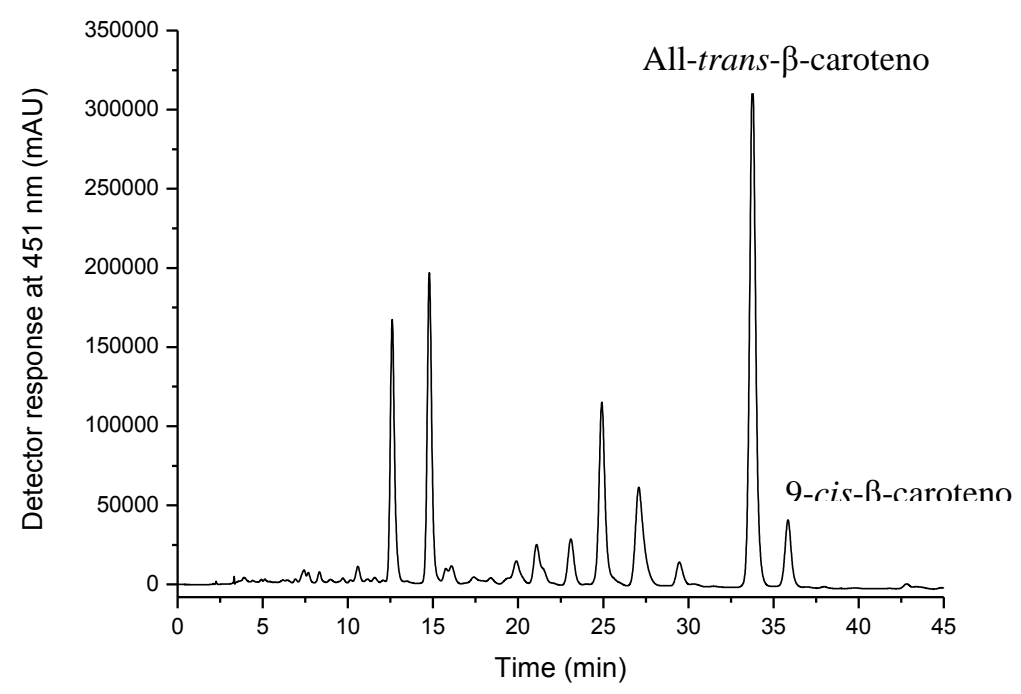

Figura 1 - Cromatograma, obtido por meio de HPLC-PDA, do extrato da biomassa de carotenoide da microalga Phormidium sp.

A biomassa pode ser considerado o primeiro bioproduto de biorrefinaria de microalgas e a produtividade do crescimento heterotrófico de Phormidium sp. em diferentes capacidades industriais é mostrada na Tabela 1. 
Tabela 1- O balanço de massa para a produção de biomassa de microalgas em diferentes capacidades industriais

\begin{tabular}{cc}
\hline Capacidade industrial $\left(\mathrm{m}^{3} / \mathrm{d}\right)$ & Produção (ton/ano) \\
\hline 100 & 5,690 \\
1,000 & 56,902 \\
10,000 & 56,9016 \\
\hline
\end{tabular}

Industrialmente, dependendo do tamanho da planta de processo é possível produzir 5.690, 56.902 e 56,9016 ton/ano de biomassa em uma pequena $(100 \mathrm{~m} 3 / \mathrm{d})$, média $\left(1.000 \mathrm{~m}^{3} / \mathrm{d}\right)$ e grande indústria $\left(10.000 \mathrm{~m}^{3} / \mathrm{d}\right)$, resultando numa produção total dos carotenoides de até $107.902,5 \mathrm{~kg} / \mathrm{ano}$. Individualmente, isso representa uma produção (Tabela 2) dos carotenoides majoritários: all-trans- $\beta$ caroteno (397,1 para 39.717,3 kg /ano) e seu isômero 9 -cis- $\beta$-caroteno (49,4 para 4,944.7 kg/ano).

O conteúdo de carotenoides totais foi de $183.03 \mu \mathrm{g} \cdot \mathrm{g}^{-1}$ de biomassa seca e representa um valor substancial quando comparada com o teor de carotenoides a partir de outras fontes, como frutas e vegetais (Rodriguez-Amaya et al., 2008).

Tabela 2- $\mathrm{O}$ balanço de massa para a produção de biomassa de microalgas em diferentes capacidades industriais

\begin{tabular}{lccc}
\hline \multicolumn{1}{c}{$\begin{array}{c}\text { Caratenóides } \\
\left(\mathrm{kg} \cdot \mathrm{kno}^{-1}\right)\end{array}$} & \multicolumn{3}{c}{ Capacidade industrial } \\
\cline { 2 - 4 } & $100\left(\mathrm{~m}^{3} \cdot \mathrm{d}^{-1}\right)$ & $1000\left(\mathrm{~m}^{3} \cdot \mathrm{d}^{-1}\right)$ & $10000\left(\mathrm{~m}^{3} \cdot \mathrm{d}^{-1}\right)$ \\
\hline Total carotenoids & $1.079,0$ & $10.790,3$ & $107.902,5$ \\
All-trans- $\beta$-carotene & 397,1 & $3.971,7$ & $39.717,3$ \\
9-cis- $\beta$-carotene & 49,4 & 494,5 & $4.944,7$ \\
\hline
\end{tabular}

\section{CONCLUSÃO}

A biomassa da microalga Phormidium sp. é mostrada como uma alternativa, renovável e uma fonte de baixo custo para obtenção de carotenoides. Demonstrou potencial para ser explorada em uma larga gama de aplicações e uma matéria prima que pode ser melhor aplicada em fins industriais.

\section{REFERÊNCIAS}


Albrecht, M., Takaichi, S., Steiger, S., Wang, Z., \& Sandmann, G. Degradation compounds of carotenoids formed during heating of a simulated cashew apple juice. Nature, v.18, p.843-846, 2009.

Britton, G., Liaaen-Jensen, S., \& Pfander, H. Carotenoids: handbook. Badel: Birkhäuser Verlag. 2004.

C. SILVA, J.M.S. CABRAL, F. VAN KEULEN, Isolation of a carotene over-producing soil bacterium, Sphingomonas sp., Biotech. Lett., v.26, p. 257-262, 2004.

DE ROSSO, V. V., \& MERCADANTE, A. Z. Identification and quantification of carotenoids, by HPLC-PDA-MS/MS, from Amazonian fruits. J. Agric. Food Chem., v.55, p.5062-5072, 2007.

FRANCISCO, E. C.; FRANCO, T. T.; WAGNER, R.; JACOB-LOPES, E. Assessment of different carbohydrates as exogenous carbon source in cultivation of cyanobacteria. Bioprocess and Biosyst. Eng., v. 36, p. 1986-2013, 2014.

G. BRITTON, The Biochemistry of Natural Pigments, Cambridge University Press, v. 21, 1983.

IP, P.; CHEN, F. Production of astaxanthin by the green microalga Chlorella zofingiensis in the dark. Process Biochem., v. 40, p.733-738, 2005.

JOHNSON, E. A.SCHROEDER W. A. Singlet oxygen and peroxyl radicals regulate carotenoid biosynthesis in Phaffia rhodozyma. J. of Biolog. Chem., v.270, p.18374-18379, 1995.

LÓPEZ, P.P.; GARCÍA, S.G.; CLAYTON, J.; AGATHOS S.N.; MCHUGH, E.; WALSH, D.; MURRAY, P.; MOANE, S.; FEIJOO, G.; MOREIRA, M. T. Life cycle assessment of the production of the red antioxidant carotenoid astaxanthin by microalgae: from lab to pilot scale. $J$. Clean. Produc., v.64, p. 332-344, 2014.

MANDELLI, F., MIRANDA, V. S., RODRIGUES, E., MERCADANTE, A. Z. Identification of carotenoids with high antioxidant capacity produced by extremophile microorganisms. $W . J$. Microb. Biotech., v.28, p. 1781-1790, 2012.

MARKOU, G.; GEORGAKAKIS, D. Cultivation of filamentous cyanobacteria (blue-green algae) in agro-industrial wastes and wastewaters: a review. Appl. Energy, v. 88, p.3389-3401, 2011.

RIPPKA, R., DERUELlES, J., WATERBURY, J. B., HERDMAN, M., \& STANIER, R. Y. Generic assignments, strain histories and properties of pure cultures of cyanobacteria. J. Gen. Microb., v.111, p. 1-61, 1979.

RODRIGUEZ-AMAYA, D. B., KIMURA, M., GODOY, H. T., AMAYA-FARFAN, J. Updated Brazilian database on food carotenoids: factors affecting carotenoid composition. J. Food Comp. Anal., v.21, p. 445-463, 2008. 
SPOLAORE, P.; JOANNIS-CASSAN, C.; DURAN, E.; ISAMBERT, A. Commercial applications of microalgae. J. Biosc. Bioeng., v.101, p. 87-96, 2006.

VAN BREEMEN, R. B., DONG, L., PAJKOVIC, N. D. Atmospheric pressure chemical ionization tandem mass spectrometry of carotenoids. I. J. Mass Spectrom., v.312, p.163-172, 2012.

ZEPKA, L. Q., MERCADANTE, A. Z. Degradation compounds of carotenoids formed during heating of a simulated cashew apple juice. Food Chem., v.117, p. 28-34, 2009. 